\title{
Integrating palaeoclimate time series with rich metadata for uncertainty modelling: strategy and documentation of the PalMod 130k marine palaeoclimate data synthesis
}

Lukas Jonkers et al.

Correspondence to: Lukas Jonkers (ljonkers@marum.de)

The copyright of individual parts of the supplement might differ from the CC BY 4.0 License. 
Search keywords used to obtain data from pangaea.de

$13 C$

$14 \mathrm{C}$

180

Age

Age AND model

alkenone

$\mathrm{B} / \mathrm{Ca}$

$\mathrm{Ba} / \mathrm{Ca}$

bulloides

C14

carbonate

$\mathrm{Cd} / \mathrm{Ca}$

chronology

cibicides

cibicidoides

d11B

d13C

d180

delta AND 11B

delta AND $13 C$

delta AND 180

dinoflagellate

dry AND bulk AND density

dutertrei

incompta

inorganic AND carbon

IRD melonis

$\mathrm{Mg} / \mathrm{Ca}$

$\mathrm{Nd}$

Neodymium

opal

organic AND carbon

$\mathrm{Pa} / \mathrm{Th}$

pachyderma

planktic AND foraminifera

planktonic AND foraminifera

protactinium

radiocarbon

ruber

sacculifer

sortable AND silt

SST

SST AND summer

SST AND winter

stable AND carbon AND isotope

stable AND oxygen AND isotope

TEX86

truncatulinoides

UK'37

UK37

uvigerina

XRF 